\title{
Pink Urine Syndrome
}

\author{
Kentaro Okubo, Hisako Okubo, Yuji Kamijo and Makoto Higuchi
}

Key words: pink urine, hyperuricemia, acidosis

(Intern Med 50: 2057, 2011)

(DOI: 10.2169/internalmedicine.50.5972)

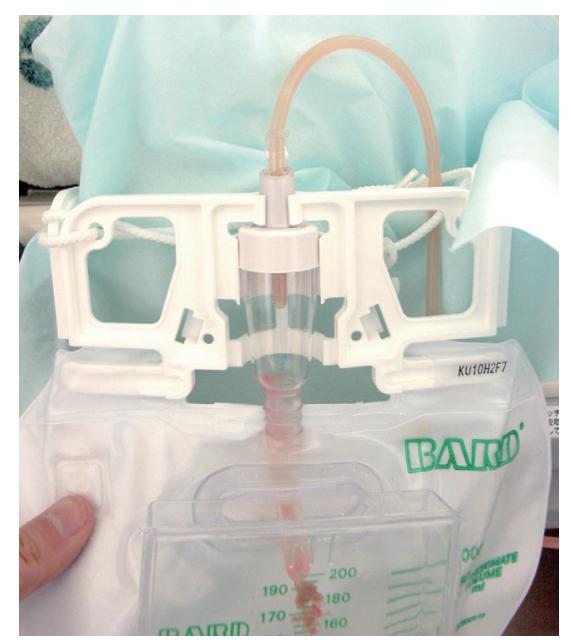

Picture 1.

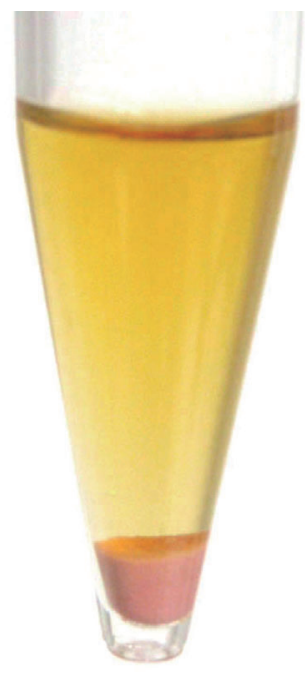

Picture 2.

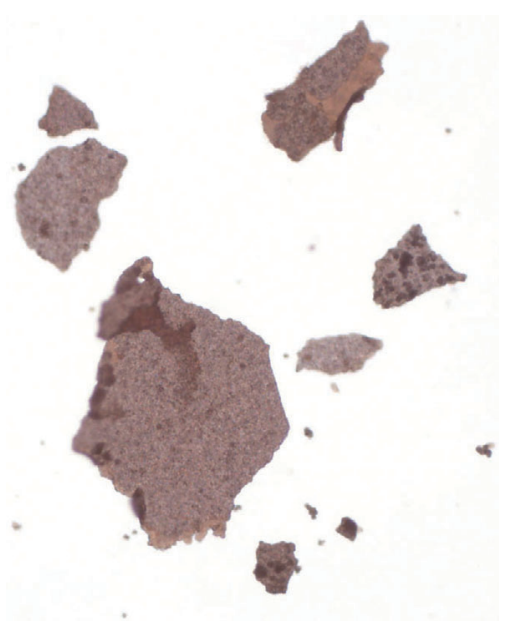

Picture 3.

A 44-year-old man suddenly excreted pink urine (Picture 1) after surgery for hepatoma. The serum biochemical examination did not indicate kidney dysfunction with hyperuricemia, except for metabolic acidosis. The pink substance was easily precipitated in the urine (Picture 2). Urinary sediment analysis showed a considerable amount of pink homogenous substance (Picture 3). Since the concentration of uric acid (UA) in the dissolved liquid and that in the patient's urine were extremely high (UA in $\mathrm{pH} 6.0$ urine, $119.4 \mathrm{mg} / \mathrm{dL}$ ), we concluded that the pink substance was amorphous UA. The solubility of UA is decreased via reduction of $\mathrm{pH}(\mathrm{pH} 7.0,200 \mathrm{mg} / \mathrm{dL}$ vs. $\mathrm{pH} 5.0,15 \mathrm{mg} / \mathrm{dL})$. The aciduria and hyperuricosuria, induced by metabolic acidosis and dehydration after the surgery, caused a deposition of amorphous UA, resulting in pink urine, which disappeared immediately when we treated the patient's dehydration and acidemia.

The authors state that they have no Conflict of Interest (COI). 